\title{
Application of artificial intelligence network to predict the distribution of volcanic material in sequence $D$, field X, Cuu Long basin
}

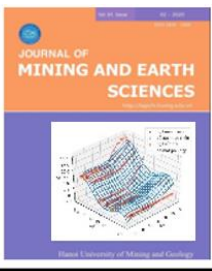

\section{Oanh Thi Tran 1, Khanh Duy Pham 2, Quy Van Hoang 3, Muoi Duy Nguyen 4, Ngan Thi Bui ${ }^{4}$ Ha Hai Thi Nguyen ${ }^{1}$, Ngoc Bao Pham ${ }^{1}$, Hiep Le Quoc ${ }^{4}$}

1 PetroVietnam University, Faculty of oil and gas

2 VietsovPetro, Exploirational Geology, Vietnam

3 Vietnam Petroleum Association, Vietnam

${ }^{4}$ Hanoi University of Mining and Geology, Faculty of oil and gas, Vietnam

\section{ARTICLE INFO}

Article history:

Received 25th June 2020

Revised 3rd Sep. 2020

Accepted 31 ${ }^{\text {st }}$ Oct. 2020

\section{Keywords:}

Artificial neural network,

D sequence,

Seismic attribute,

Volcanic materials.

\section{ABSTRACT}

The presence of volcanic materials in reservoir will reduce the porosity value and effect to the quality of reservoirs. Therefore, understanding the distribution of this object will be of great significance in the orientation of oil and gas exploration and exploitation. This paper applies seismic attribute analysis method combined with artificial neural network (ANN) application to predict the distribution of volcanic materials in D sequence. Attributes selected as input for ANN training including RMS, RAI and Specdecom attribute. The results indicate that volcanic materials mainly appear in the to the Southwest of block (around D well and the West of $E$ well), a small part is scattered near Con Son swell. The correlation coefficient among seismic attribute is from 71 to $~ 80 \%$, this shows that the reliability of the results of network training is relatively high. Therefore, this method can be used to predict the distribution of volcanic materials in the study area.

Copyright (C) 2020 Hanoi University of Mining and Geology. All rights reserved.

${ }^{*}$ Corresponding author

E - mail: oanhtran@pvu.edu.vn

DOI: 10.46326/JMES.2020.61(5).12 


\title{
Tạp chí Khoa học Kỹ thuật Mỏ - Địa chất
}

Trang điện tử: http://tapchi.humg.edu.vn

\section{Ứng dụng mạng trí tuệ nhân tạo dự báo phân bố vật liệu núi lửa trong tập $\mathrm{D}$, mỏ X, bể Cửu Long}

\author{
Trần Thị Oanh ${ }^{1}$, Phạm Duy Khánh ${ }^{2}$, Hoàng Văn Quý ${ }^{3}$, Nguyễn Duy Mười ${ }^{4}$, Bùi Thị \\ Ngân ${ }^{4}$, Nguyễn Thị Hải Hà ${ }^{1}$, Phạm Bảo Ngọc ${ }^{1}$, Lê Quốc Hiệp ${ }^{4}$ \\ ${ }^{1}$ Trường đại học Dầu khí Việt Nam, Khoa Dầu khí, Việt Nam \\ 2 VietsovPetro, Phòng Địa chất Thăm dò, Việt Nam \\ ${ }^{3}$ Hội dầu khí Việt Nam, Việt Nam \\ ${ }^{4}$ Trường Đại học Mỏ - Địa chất, Khoa Dầu khí, Việt Nam
}

\begin{tabular}{|c|c|}
\hline THÔNG TIN BÀI BÁO & TÓM TẮT \\
\hline $\begin{array}{l}\text { Quá trình: } \\
\text { Nhận bài } 25 / 6 / 2020 \\
\text { Sưa xong 3/9/2020 } \\
\text { Chấp nhận đăng 31/10/2020 } \\
\text { Tù̀ khóa: } \\
\text { Mạng nơoron nhân tạo, } \\
\text { Tập D, } \\
\text { Thuộc tính địa chấn, } \\
\text { Vật liệu núi lửa. }\end{array}$ & 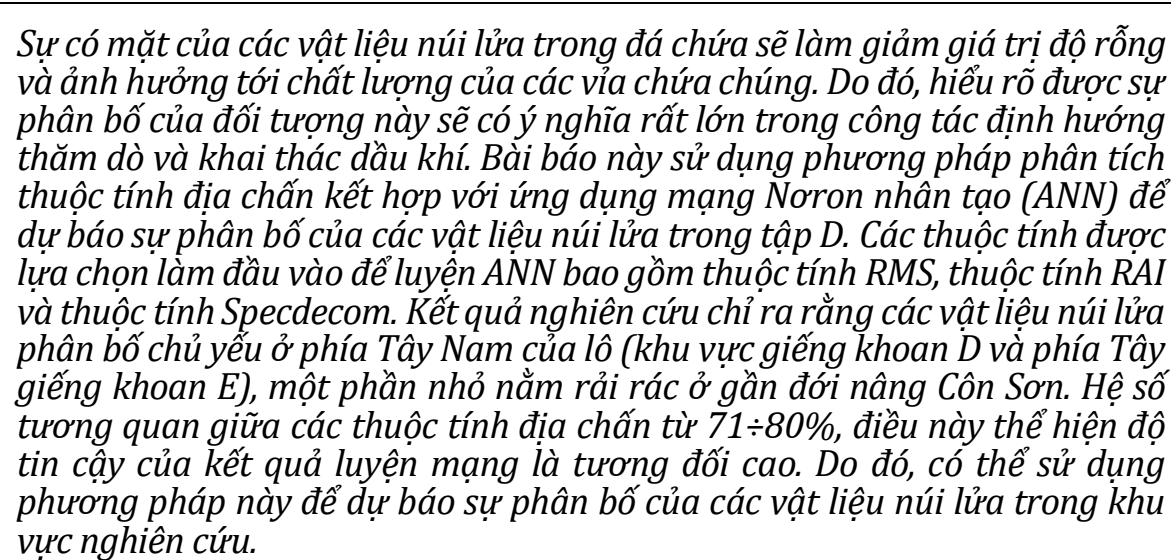 \\
\hline
\end{tabular}

(C) 2020 Trường Đại học Mỏ - Địa chất. Tất cả các quyền được bảo đảm.

\section{Mở đầu}

Mỏ X thuộc lô 09.3/12 có diện tích 5.559 km², nằm ở phần rìa đông nam bể Cửu Long (Hình 1 ) và có đặc điểm cấu - kiến tạo nằm trong bối cảnh kiến tạo chung của bể. Kiến trúc của bể được chia

"Tác giả liên hệ

E - mail: oanhtran@pvu.edu.vn

DOI: 10.46326/JMES.2020.61(5).12 thành ba tầng chính: móng trước Kainozoi, Oligocen và Miocen-Pleistocen (NIPI, 2016).

Trong giai đoạn Mezozoi, bể Cửu Long nằm trong khu vực chịu ảnh hưởng của hoạt động hút chìm mảng Thái Bình Dương. Vào giai đoạn cuối Creta-đầu Paleogen xảy ra quá trình nâng lên và kết quả là đá móng được nâng lên và trải qua một quá trình bào mòn phong hoá kéo dài. Các hoạt động kiến tạo trong khu vực đã tạo ra hình thái khá đặc trưng và phức tạp của mặt móng, gây ra 


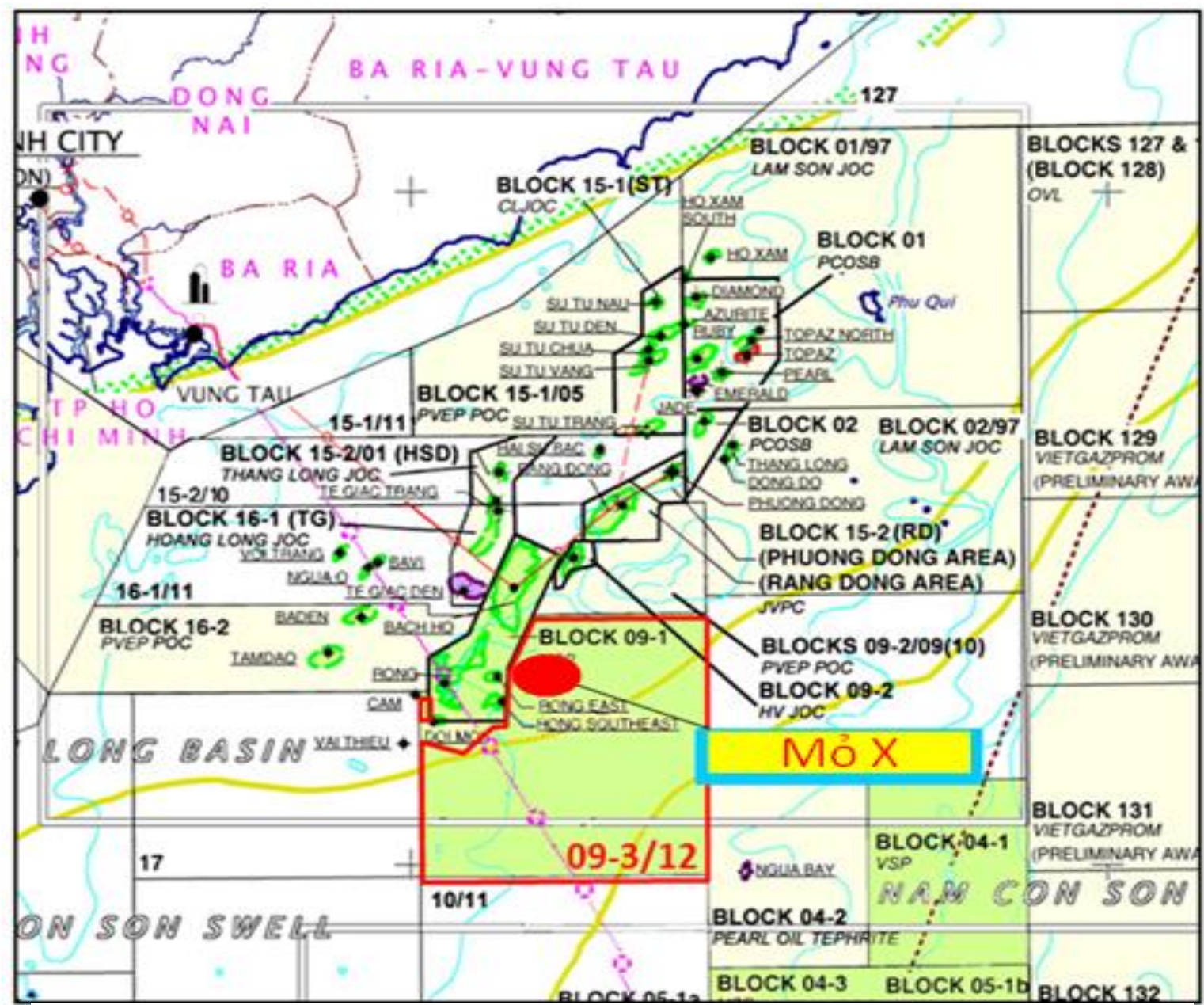

Hình 1. Vị trí khu vực nghiên cúu (NIPI, 2016).

hàng loạt đứt gãy và chia cắt tầng móng thành các triền võng và các khối nhô khác nhau.

Tầng kiến trúc Oligocen nhìn chung phát triển kế thừa mặt móng. Tất cả các yếu tố cấu trúc chính hầu hết được kế thừa từ móng và xuất hiện trong giai đoạn Oligocen. Về mặt hình thái, ảnh hưởng của các cấu trúc tầng móng đối với tầng Oligocen, theo mặt cắt, có xu thế giảm dần từ dưới lên trên.

Hệ thống đứt gãy ĐB-TN đã lộ thiên trên đất liền và chúng hầu hết là những đứt gãy cổ rất có thể đã được hình thành vào Oligocen sớm hoặc Eocen muộn. Pha tách giãn muộn tiếp tục xảy ra vào cuối Oligocen sớm. Vào giai đoạn cuối Oligocen sớm-đầu Oligocen muộn pha tách giãn được thay thế bởi pha nén ép mà được đặc trưng bởi hoạt động nâng lên, bào mòn mạnh mẽ ở đỉnh của các cấu tao.

Từ Oligocen muộn tới Miocen sớm đã xảy ra quá trình lún chìm ở bể Cửu Long. Quá trình lún chìm này xảy ra gián đoạn ít nhất là hai lần. Tầng kiến trúc Miocen-Pleistocen được đặc trưng bởi địa hình tương đối bằng phẳng và mức độ suy giảm nhanh chóng về số lượng các đứt gãy.

\section{Cơ sở tài liệu và phương pháp nghiên cứu}

Tài liệu được sử dụng trong bài báo bao gồm tài liệu địa chấn 3D Pr PSDM với diện tích 856 km². Các bước xử lý tài liệu địa chấn đã nâng cao chất lượng và tính liên tục của tín hiệu địa chấn, giảm bớt các nhiễu và có thể đảm báo để sử dụng cho việc phân tích thuộc tính địa chấn một cách chính xác. Ngoài ra, trong bài báo này còn sử dụng các tài liệu đo ĐVLGK của 05 giếng khoan trong khu vực nghiên cứu, báo cáo phân tích thạch học của các giếng khoan trong mỏ X để luận giải sự phân bố của các trầm tích có mặt trong khu vực.

Nhóm tác giả minh giải các tài liệu địa vật lý giếng khoan và tài liệu địa chấn nhằm đánh giá sự tương quan về đặc điểm thạch học của hai loại tài liệu này. Trên cơ sở đó, kết hợp với tài liệu môi 
trường trầm tích để xây dựng các bản đồ thuộc tính địa chấn, các thuộc tính được lựa chọn sẽ được tính hợp làm đầu vào cho việc luyện mạng "Neural net"- đây là một ứng dụng của mạng trí tuệ nhân tạo được tích hợp trong phần mềm Petrel và được xây dựng bởi công ty Slumberger. Công cụ này được sử dụng để đánh giá/ dự báo sự thay đổi tướng trầm tích, thành phần thạch học hoặc dự báo sự phân bố của các thân cát bằng thuật toán luyện có kiểm soát (Supervised) hoặc luyện không kiểm soát (Unsupervised).Người dùng sẽ sử dụng kỹ thuật principal component analysis (PCA) hoặc Correlation analysis để kiểm tra độ tương quan của các input, cũng như giảm thiểu tối đa các số liệu đầu vào không cần thiết (David Lubo- Robles và Kurt J. Marfurt, 2018).Quá trình luyện được lặp đi lặp lại nhiều lần, vào cuối mỗi lần lặp quy trình sẽ kiểm tra kết quả và nếu các tiêu chí không được đáp ứng thì nó sẽ luyện lại cho tới khi đạt được kết quả như mong muốn. Phương pháp Supervised cần phải được cung cấp mẫu luyện và kết quả mong muốn, trong khi đó Unsupervised sẽ chia nhỏ dữ liệu đầu vào thành các lớp theo mong muốn của người sử dụng(Coleou, T., M. Poupon và K. Azbel, 2003). Trong phạm vi bài báo này, nhóm sử dụng phương pháp luyện không kiểm soát (Unsupervised), quy trình thực hiện được thể hiện ở Hình 2. Quy trình này được xây dựng dựa trên cơ sở lý thuyết và ứng dụng các thuộc tính địa chấn trong TKTD dầu khí cũng như việc tham khảo các tài liệu liên quan (Phan Thanh Liêm và Lê Hải An, 2013; VSP, 2017). Trong bài báo này, nhóm tác giả sử dụng 3 thuộc tính địa chấn cơ bản như: RMS, RAI, và Specdecom để tiến hành phân tích. Đây là các thuộc tính phản ánh khá chính xác sự thay đổi về mặt thạch học, tướng trầm tích từ đó sẽ có cái nhìn rõ ràng hơn về bức tranh phân bố của các vật liệu trầm tích khác nhau trong khu vực nghiên cứu.

\subsection{Thuộc tính trở kháng âm học tưong đối (RAI)}

Đây là một phép chạy tổng các giá trị biên độ được lấy mẫu bình thường. Phép tính được thực hiện bằng việc tích hợp mạch địa chấn, đẩy kết quả qua một bộ lọc Butterworth tần cao nhằm giảm tiềm năng nhiễu tần số thấp đưa vào. Bộ lọc Butterworth này được áp dụng như một bộ lọc low-cut mà không có tỷ lệ. Do đó, phạm vi kết quả có giá trị sẽ lớn hơn và rõ ràng hơn trước (Satinder Chopra Kurt J. Marfurt, 2007). Kết quả khảo sát cho thấy thuộc tính RAI có độ phân giải thẳng đứng cao hơn so với các thuộc tính biên độ. Ngoài ra trên bức tranh thuộc tính RAI tính liên tục của sóng phản xạ cũng được cải thiện đáng kể. Thuộc tính này được ứng dụng để phản ánh độ tương phản âm học biểu kiến, chỉ ra các ranh giới tập, các bề mặt bất chỉnh hợp và gián đoạn, cũng có thể chỉ ra độ rỗng hoặc hàm lượng chất lưu trong tầng.

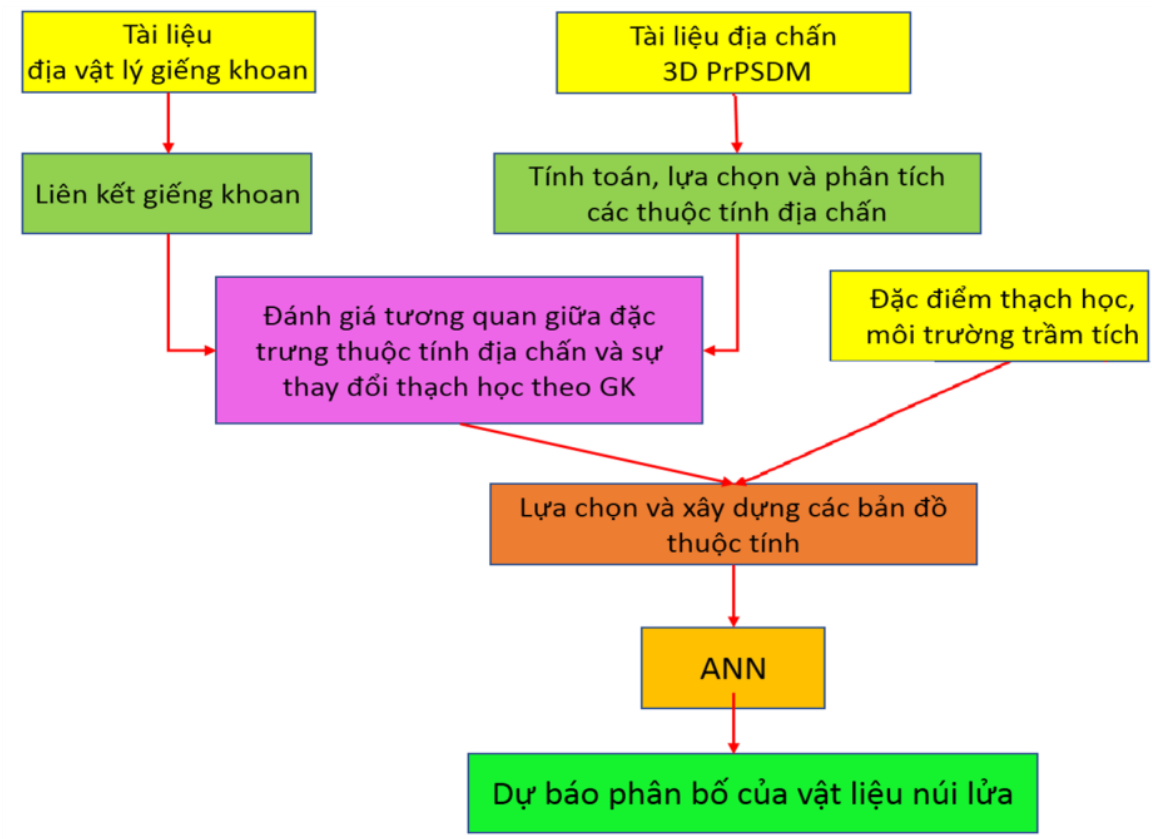

Hình 2. Quy trình thực hiện dự báo phân bố vật liệu trầm tích. 


\subsection{Thuộc tính biên độ bình phương trung bình - Root Mean Square Amplitude (RMS)}

Phương pháp thuộc tính biên độ là một trong những thuộc tính địa chấn cơ bản của các mạch địa chấn, phương pháp sử dụng các công thức phân tích giá trị biên độ trong cửa sổ định sẵn với các mục đích sau: Xác định các tầng chứa dầu khí; Tính độ dày tổng, độ rỗng tổng; Xác định các kênh rạch, Nhận dạng mặt bất chỉnh hợp; Thay đổi địa tầng trầm tích.

Thuộc tính biên độ địa chấn RMS được sử dụng rộng rãi trong công tác xử lý và minh giải tài liệu địa chấn với mục đích xác định và dự báo phân bố các đặc trưng địa chất, địa tầng, cấu trúc và đặc trưng đá chứa, hệ thống đứt gãy của các tầng minh giải. Thuộc tính RMS thường được dùng kết hợp với các thuộc tính địa chấn khác như SpecDecom, RAI, Sweetness, Instantenous Frequency nhằm tăng khả năng hỗ trợ dự báo phân bố đá chứa (Enwenode Onajite, 2014).

\subsection{Các thuộc tính liên quan đến Phương pháp SpecDecom (Phổ tần số tức thò̀i)}

Phương pháp này chuyển đổi tài liệu địa chấn từ lát cắt thời gian sang lát cắt tần số thông qua phép toán DFT (Discrete Fourier Transform). Biên độ phổ tần số hay pha được sử dụng để xác định sự phân bố theo chiều ngang các đặc trưng địa chất. Do đó, phương pháp Specdecom được ứng dụng để: Xác định sự phân bố tướng đá (facies) và các đặc điểm trầm tích của đá chứa (ranh giới môi trường trầm tích, phân bố sông ngòi,...); Xác định thứ tự trầm tích của các tầng địa chất; Vẽ và chính xác hóa hệ thống đứt gãy.; Xây dựng mô hình đá chứa (xây dựng bản đồ chất lưu, dị thường áp suất...) (Mirza Naseer Ahmad, Philip Rowell, 2012.)

\section{Kết quả nghiên cứu}

\subsection{Kết quả phân tích thuộc tính địa chấn}

Trầm tích Oligocen $\mathrm{D}$ bao gồm các lớp cát bột sét xen kẹp, các tập cát kết có cấu tạo khối phân lớp mỏng -ngang hoặc uốn lượn, xen kẹp với các lớp sét rất mỏng Đá có độ hạt từ nhỏ-trung-lớn, độ chọn lọc từ trung bình đến kém, tiếp xúc hạt dạng điểm đường. Thành phần khoảng vật chính là thạch anh, fenspat, mica và mảnh đá (NIPI, 2016). Theo các tài liệu minh giải ĐVLGK và báo cáo mô tả thạch học của mỏ $\mathrm{X}$, thì phần trên của tập $\mathrm{D}$, trầm tích Oligocen trên tương ứng với tập vỉa từ D0-D3 (Hình 3), phân bố từ độ sâu 2.863,5-

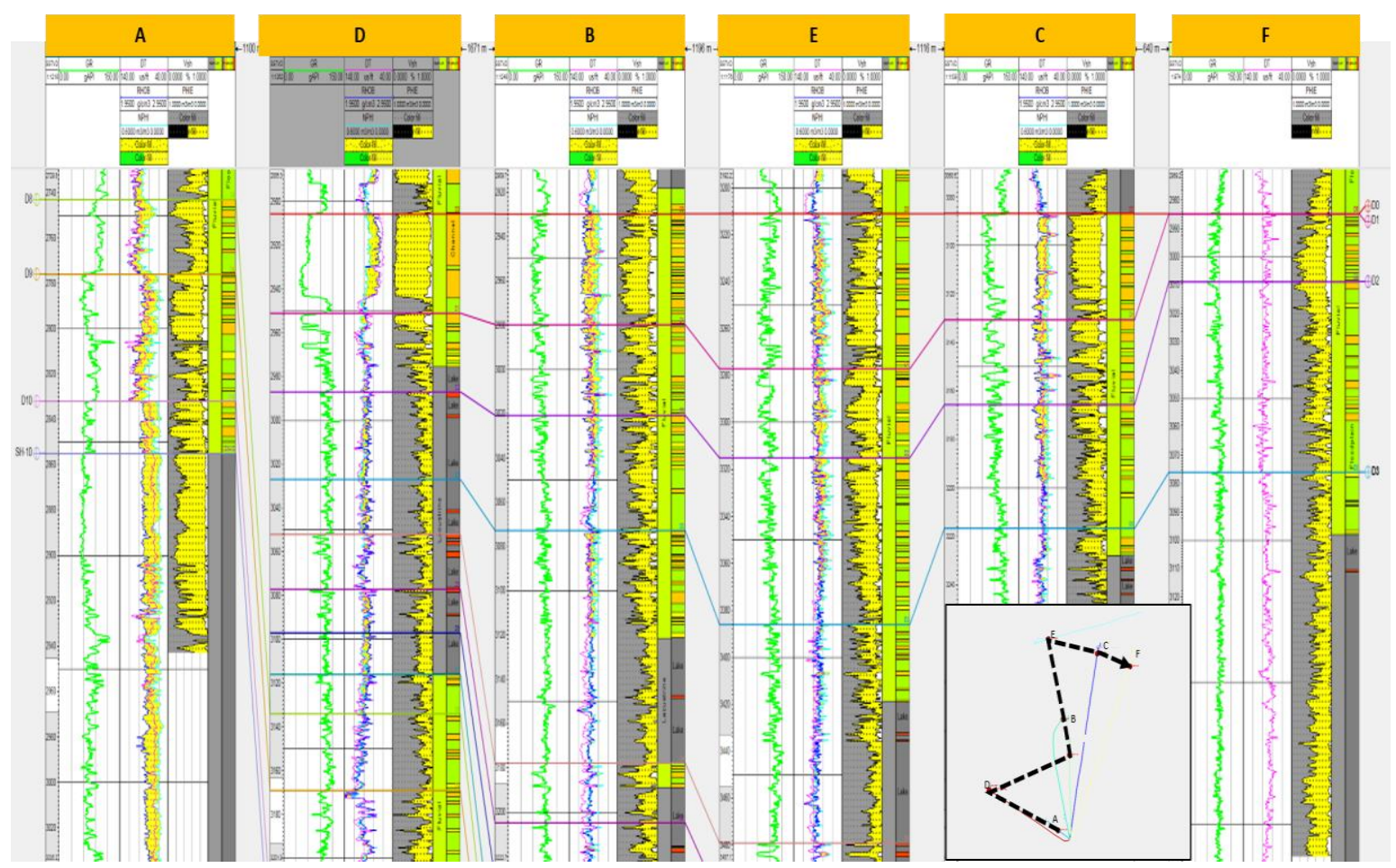

Hình 3. Tuyến liên kết cắt lần lượt qua các giếng $A, D, B, C, E, F$. 


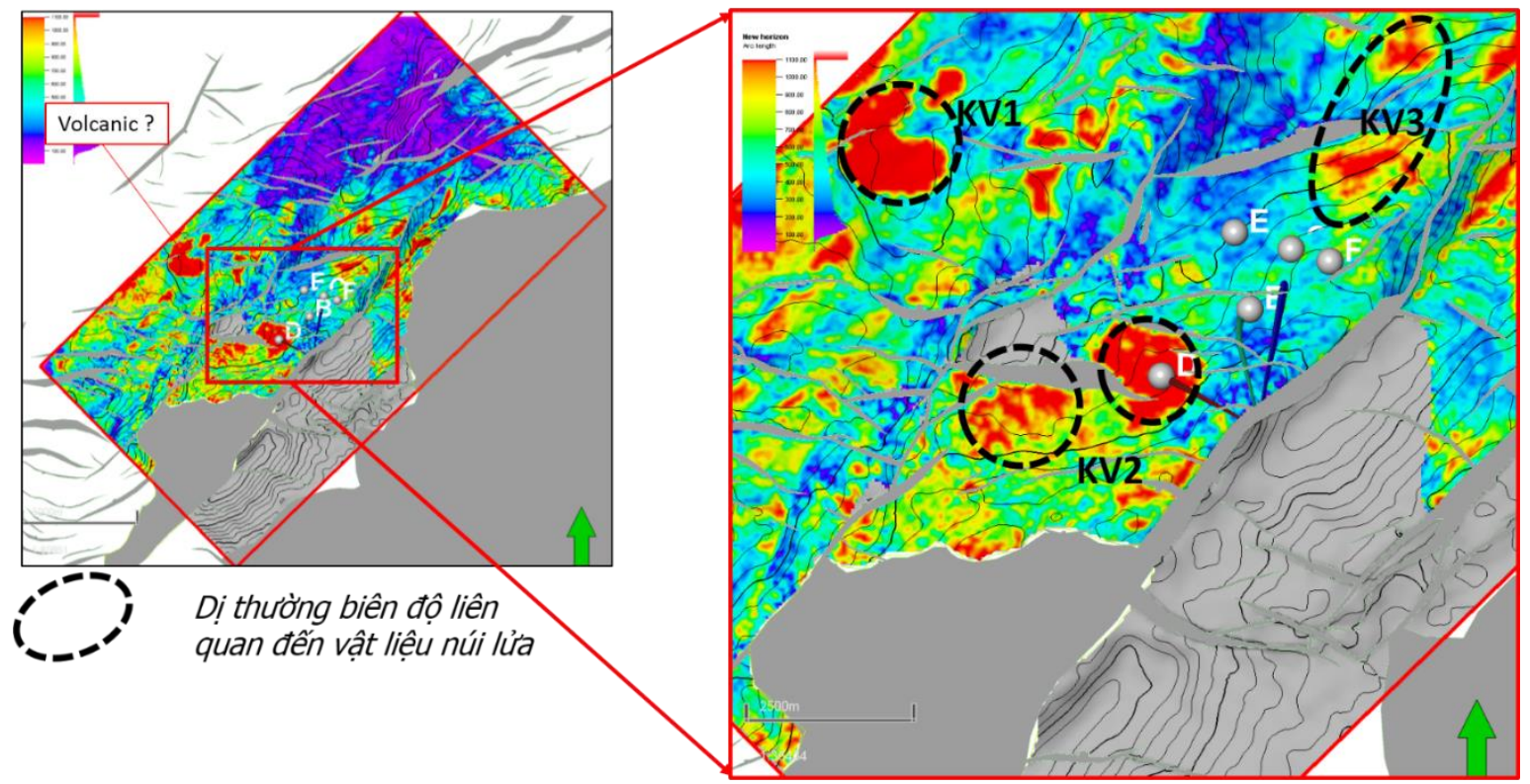

Hình 4. Bản đồ thuộc tính RMS (20 ms) cho phần trên của tập D.

$3.409,5$ m. Đây là các vỉa cát mỏng, có bề dày dao động từ $4 \div 25 \mathrm{~m}$, độ rỗng dao động từ $12 \div 22 \%$.

Kết quả phân tích thuộc tính Specdecom $17 \mathrm{~Hz}$ (20 ms), thuộc tính RMS (20 ms) và thuộc tính RAI (20 ms) cho thấy ở khu vực mỏ X có chứa nhiều thân cát khác nhau, nằm phân bố rộng khắp khu vực nghiên cứu. Đặc biệt, trên bản đồ phân bố của ba thuộc tính này cho thấy các dị thường biên độ mạnh, đây có thể là dấu hiệu liên quan tới các vật liệu núi lửa, đặc biệt là ở giếng khoan D (Hình 4, 5 và 6). Trên cơ sở lập luận trên, có thể khoanh định được ít nhất 3 khu vực có dấu hiệu của vật liệu núi lửa: khu vực 1 bao phủ giếng $\mathrm{D}$, khu vực hai nằm ở sườn Đông Nam có phương á Đông Tây, khu vực 3 nằm ở phía Tây Bắc giếng $\mathrm{E}$.

Trên mặt cắt địa chấn qua khu vực có sự xuất hiện của vật liệu núi lửa không quan sát thấy hình ảnh dạng nấm (thường liên quan tới hoạt động phun nổ của núi lửa) mà chỉ thấy biểu hiện của các phản xạ mạnh và biên độ cao trên mặt cắt địa chấn

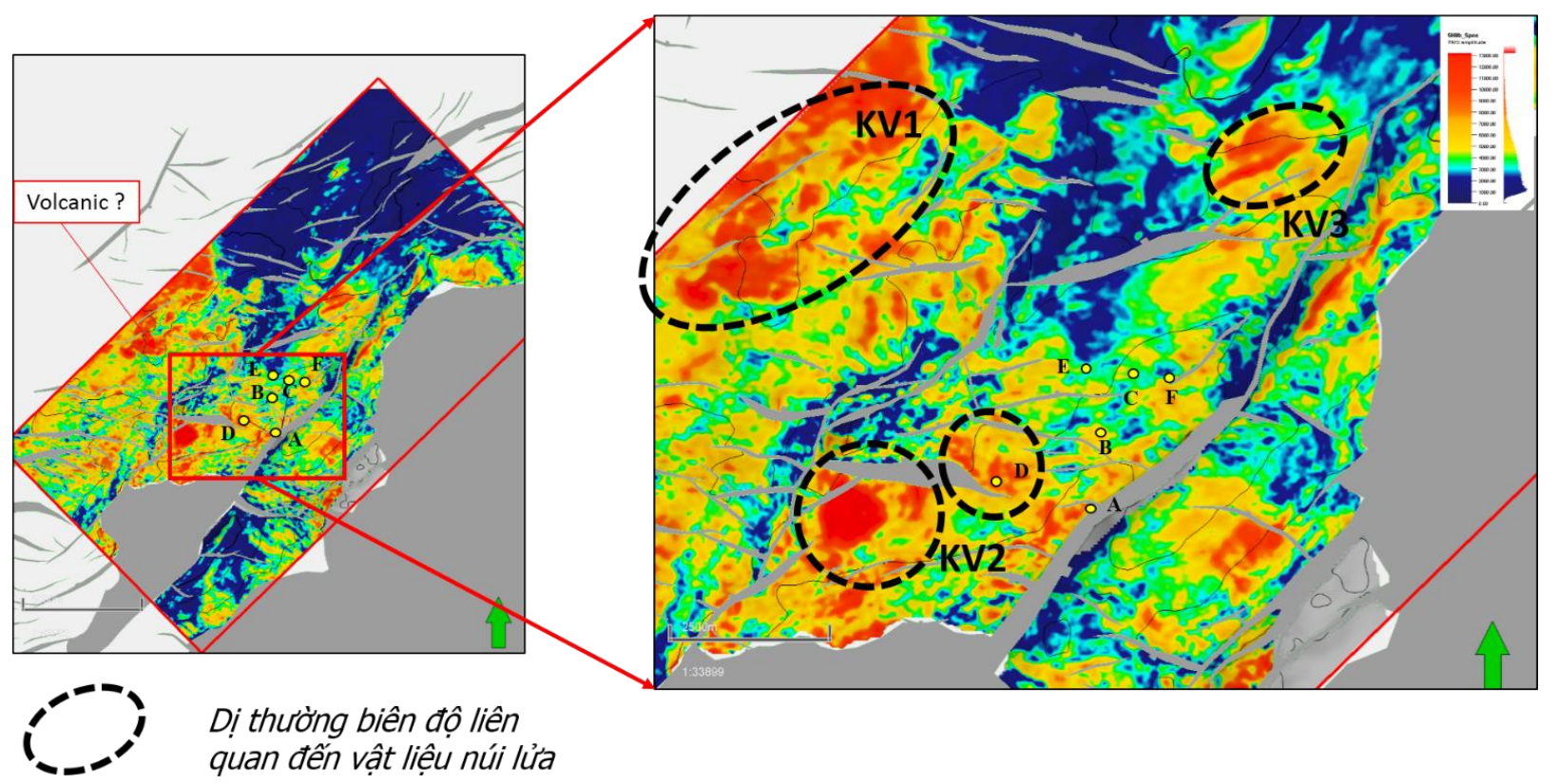

Hình 5. Bản đồ thuộc tính Specdecom ưng với tần số $17 H z$ cho phần trên của tập D (-20ms). 


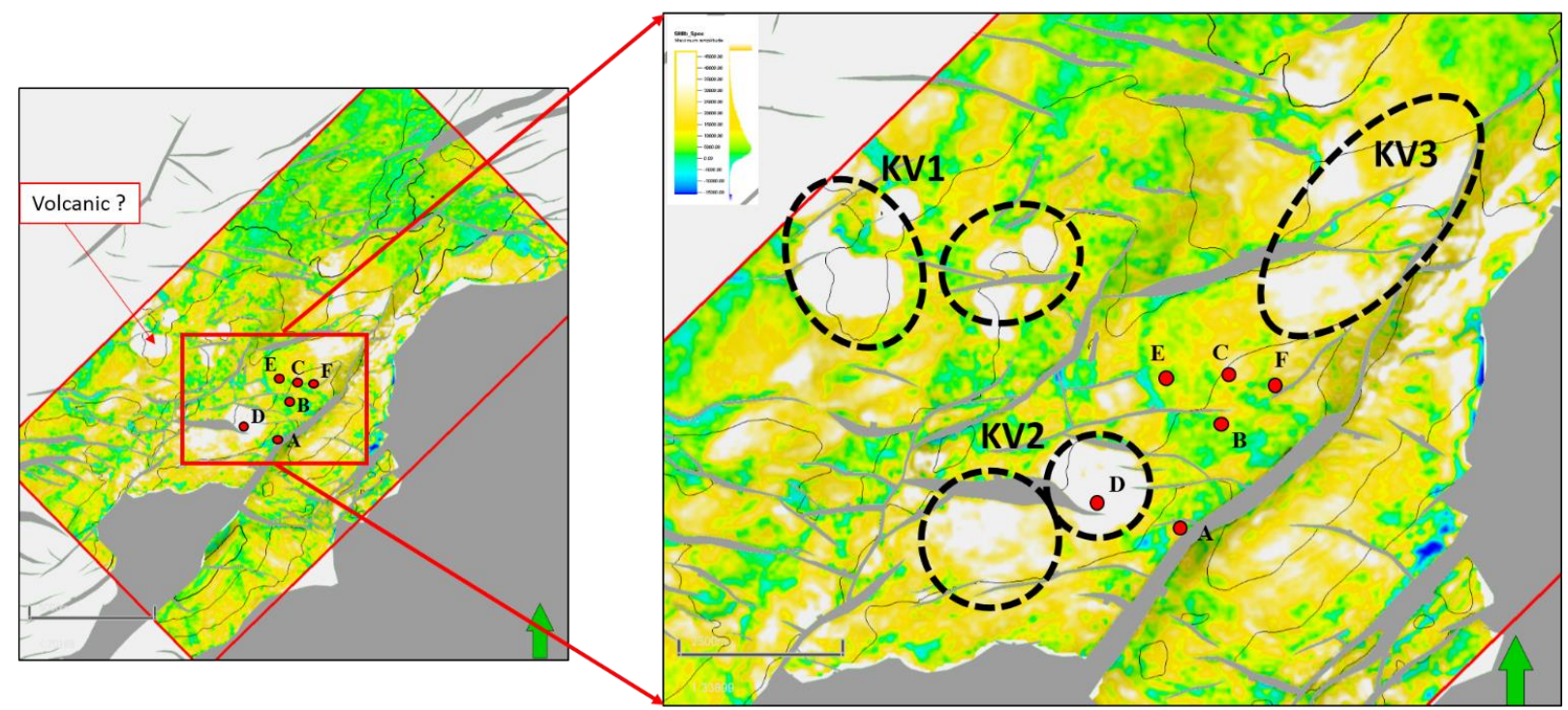

Hình 6. Bản đồ thuộc tính RAI (20ms) dự báo khu vực có hoạt động núi lửa.

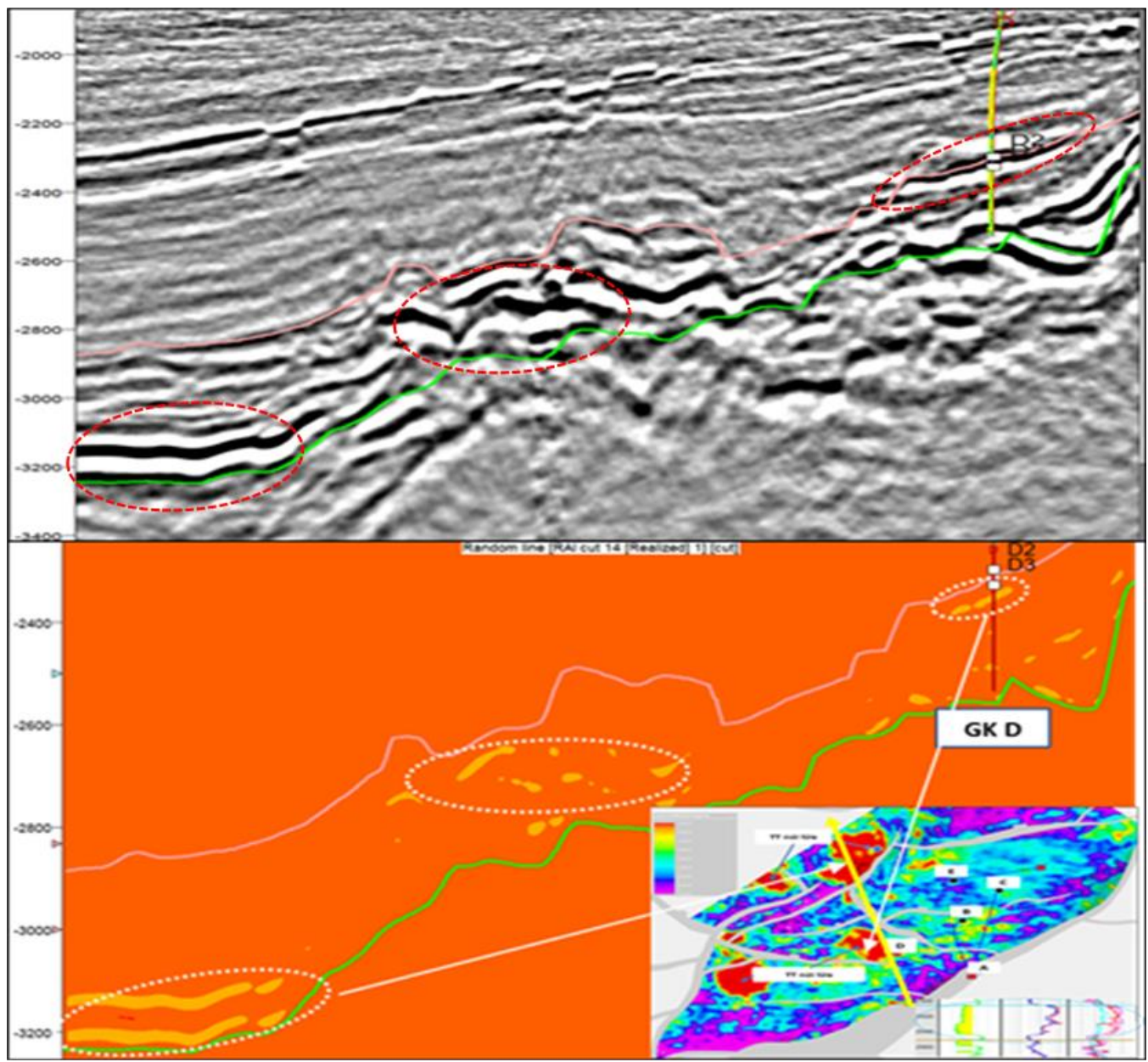

Hình 7. Mặt cắt địa chấn và thuộc tính địa chấn RAI dự báo khu vực có vật liệu núi lửa.

(Hình 7) nên có thể chúng được hình thành theo dạng xâm nhập, chảy tràn hoặc bóc mòn từ bề mặt móng do quá trình nâng lên. Sự có măt của các vật liệu núi lửa có thể là nguyên nhân làm suy giảm 
chất lượng đá chứa (tại những vỉa có chứa chúng). Ví dụ: Vỉa D2 (3514 $\div 3554$ mMD) của giếng khoan $\mathrm{D}$ có độ rỗng trung bình xấp xỉ $8 \div 10 \%$ trong khi vỉa cát kết (3560 $\div 3570 \mathrm{mMD})$ có độ rỗng trung bình lên đến $23 \%$. Nguyên nhân có thể là do trầm tích núi lửa chứa nhiều mảnh đá, khoáng vật thứ sinh lấp nhét do đó làm giảm độ rỗng.

Trên đường cong địa vật lý giếng khoan, biểu hiện của vật liệu núi lưa là trên đường cong đo ghi địa vật lý giếng khoan là hiện tượng giảm mạnh về giá trị trong đường cong độ trễ DT ứng với tăng vận tốc khi đi qua lớp trâm tích có sự xuất hiện của các vật liệu núi lửa. Ngoài ra, cũng quan sát thấy tại vỉa có chứa vật liệu núi lửa có sự tăng mạnh của đường RHOB so với các vỉa cát (Hình 8).

\subsection{Kết quả úng dụng mạng nơron nhân tạo ANN}

Mỗi thuộc tính đều có một chức năng riêng và thể hiện một đặc trưng hoặc một tín hiệu riêng biệt. Chính vì thế, để đánh giá tổng thể sự phân bố của một đối tượng địa chất cụ thể, chúng ta cần phải sử dụng tổ hợp các thuộc tính địa chấn bằng cách tích hợp cùng lúc nhiều thuộc tính bằng phương pháp mạng nơron nhân tạo, phương pháp này cho phép phân chia các tướng địa chấn theo các đặc trưng của các tập trầm tích (Lê Hải An, 2016). Mạng Nơron nhân tạo được sử dụng khá phổ biến trong lĩnh vực tìm kiếm thăm dò dầu khí để phân chia các tướng địa chấn hoặc để dự báo độ rỗng, độ thấm của đá chứa.

Có hai phương pháp phân chia tướng địa chấn theo ANN: phân chia theo phương pháp luyện có kiểm soát (Supervised) và phân chia theo phương pháp luyện không kiểm soát (Unsupervised). Trong bài báo này, nhóm tác sử dụng phân chia tướng theo phương pháp luyện không kiểm soát dựa trên thuật toán phân cụm (clustering) để phân chia tướng địa chấn. Phương pháp này chỉ dựa vào hệ số liên kết giữa các thuộc tính địa chấn mà không cần kiểm soát bởi kết qủa giếng khoan.

Trước hết, nhóm tác giả đã tiến hành phân chia các tướng địa chấn ra 03 loại (seismic class): tướng cát (class I), tướng sét (class II) và trầm tích

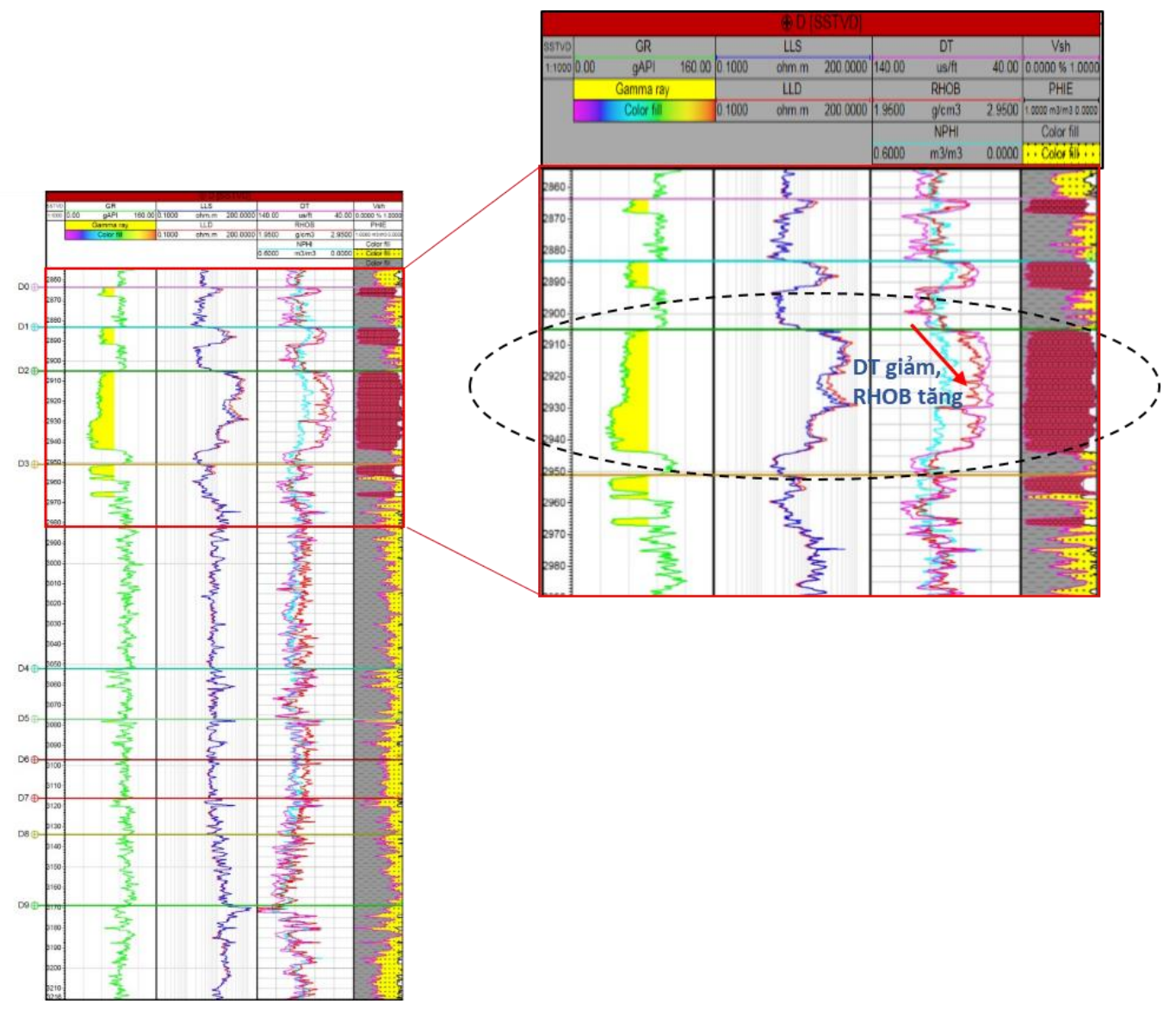

Hình 8. Biểu hiện của vật liệu núi lửa trên đường cong ĐVLGK. 
núi lửa (class III) tương ứng với các loại vật liệu trầm tích có mặt trong khu vực nghiên cứu. Các thuộc tính được lựa chọn làm đầu vào là thuộc tính RMS, Specdecom, RAI. Đây là các thuộc tính đã phản ánh rõ nét nhất về phân bố của các thân cát và vật liệu núi lửa như đã được trình bày ở phần trên. Các thuộc tính này được đưa vào mạng nơron nhân tạo để phân loại tướng nhằm nhận dạng và khoanh vùng phân bố của các vật liệu trầm tích cát, sét và núi lửa. Kết quả mô hình ANN cho thấy các vật liệu núi lửa được phân bố tập trung chủ yếu tại khu vực phía Tây Nam của mỏ X (tại giếng khoan $\mathrm{D}$ và rìa phía Tây), ngoài ra phân bố rời rạc và nằm rải rác tại khu vực gần đới nâng Côn Sơn (Hình 9). Kết quả chạy ANN cũng chỉ ra rằng các thân cát phân bố rộng khắp khu vực mỏ $X$ và có dạng "stack" được cung cấp vật liệu từ các đới nâng Côn Sơn và đới nâng Sói.

Trên cơ sở phân tích 03 thuộc tính địa chấn và sử dụng chúng để làm số liệu đầu vào để luyện mạng ANN. Kết quả đầu ra của mô hình là bản đồ phân bố cát-sét và trầm tích núi lửa trong khu vực nghiên cứu, kết quả này có độ tin cậy cao với hệ số tương quan giữa các thuộc tính lên tới gần $80 \%$ (Bảng 1). Xu thế phân bố này cũng hoàn toàn phù hợp với các nghiên cứu trước đó về môi trường của mỏ X. Vì vậy, có thể sử dụng kết quả này để khoanh vùng và dự báo sự phân bố của vật liệu trầm tích núi lửa cũng như sự phân bố của các thân cát có mặt trong khu vực nghiên cứu.

\section{Kết luận}

Bài viết đã đưa ra khoanh vùng được vị trí phân bố của các vật liệu núi chủ yếu dựa trên việc áp dụng phương pháp phân tích các thuộc tính địa chấn và ứng dụng mạng $\mathrm{ANN}$ với phương pháp luyện không kiểm soát.

Trên các bản đồ thuộc tính địa chấn, đối tượng này thường có dị thường biên độ rất mạnh so với các vật liệu trầm tích khác. Kết quả của mô hình ANN sau khi tích hợp các thuộc tính địa chấn để

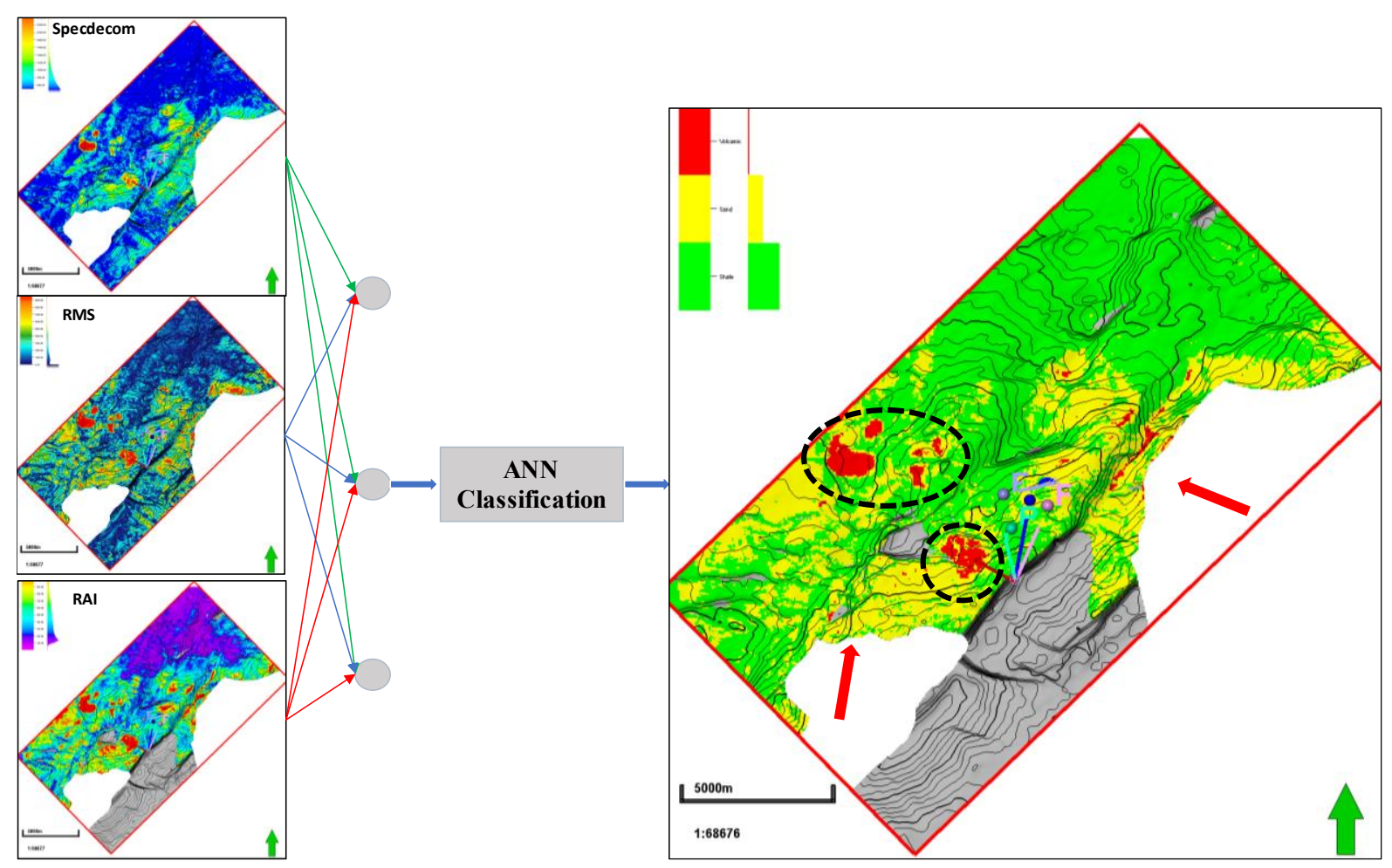

Hình 9. Mô hình và kết quả chạy ANN dự báo phân bố của các vật liệu núi lưa và các thân cát, phần trên tập D.

Bảng 1. Kết quả đối sánh hệ số tương quan giữa kết quả luyện ANN với các thuộc tính địa chấn.

\begin{tabular}{|c|c|c|c|}
\hline & Thuộc tính RMS & Thuộc tính Specdecom & Thuộc tính RAI \\
\hline Thuộc tính RMS & 1.0000 & 0.6580 & 0.6838 \\
\hline Thuộc tính Specdecom & 0.6580 & 1.0000 & 0.7598 \\
\hline
\end{tabular}


phân loại tướng đã chỉ ra rằng các vật liệu trầm tích núi lửa phân bố chủ yếu ở phía Tây Nam của lô (khu vực giếng khoan $\mathrm{D}$ và phía Tây giếng khoan $\mathrm{E}$ ), một phần nhỏ nằm rải rác gần đới nâng Côn Sơn.

Các kết quả trong bài báo đã đưa ra được bức tranh phân bố của các vật liệu núi lửa, điều này có ý nghĩa rất lớn cho việc cho việc định hướng thăm dò khai thác trong giai đoạn tiếp theo của khu vực nghiên cứu.

\section{Lò̀i cảm on}

Nội dung bài báo nhằm công bố một số kết quả nghiên cứu đạt được trong quá trình thực hiện đề tài: "Nghiên cứu sự phân bố của đá chứa cát kết Oligocen trên, cấu tạo X, bể Cửu Long, trên cơ sở phân tích thuộc tính địa chấn và ứng dụng mạng Nơron nhân tạo" do Trường Đại học Dầu khí Việt Nam chủ trì. Các tác giả xin chân thành cảm ơn Trường Đại học Dầu khí Việt Nam đã tạo điều kiện cho chúng tôi tham gia thực hiện đề tài để có cơ sở tài liệu viết bài báo này.

\section{Những đóng góp của tác giả}

Tác giả Trần Thị Oanh thu thập tài liệu, minh giải tổng hợp tài liệu và viết báo. Tác giả Phạm Duy Khánh phân tích thuộc tính địa chấn. Tác giả Hoàng Văn Quý kiểm tra kết quả phân tích và cố vấn chỉnh sửa bài báo. Tác giả Nguyễn Duy Mười thu thập tài liệu về tướng trầm tích. Tác giả Bùi Thị Ngân thu thập tài liệu về trí tuệ nhân tạo và ứng dụng. Tác giả Nguyễn Thị Hải Hà phân tích một phần thuộc tính địa chấn khu vực nghiên cứu. Tác giả Phạm Bảo Ngọc phân tích tài liệu địa chất khu vực nghiên cứu. Tác giả Lê Quốc Hiệp tổng hợp tài liệu.

\section{Tài liệu tham khảo}

Coleou, T., M. Poupon, and K. Azbel, (2003). Unsupervised seismic facies classification: A review and comparison of techniques and implementation. The Leading Edge, 22, 942953.
David Lubo-Robles and Kurt J. Marfurt, (2018). Unsupervised seismic-facies classification using independent-component analysis. SEG International Exposition and 88th Annual Meeting, October 14-19 Oct, North Americar, Society of Exploration Geophysicists, 16031607.

Enwenode Onajite, (2014). Seismic Data Analysis Techniques in Hydrocarbon Exploration. Elsevier, 256.

IGS, (2018). Báo cáo kết quả phân tích mẫu lõi (sidewall core) đặc biệt giếng D. VSP.

Lê Hải An, (2016). Báo cáo "Phân tích tổ hợp thuộc tính địa chấn nhằm dự báo sự phân bố và đặc tính của đá chứa trong lát cắt trầm tích Mioxen và Oligoxen, lô 09-3/12. VSP.

Mirza Naseer Ahmad, Philip Rowell, (2012). Application of spectral decomposition and seismic attributes to understand the structure and distribution of sand reservoirs within Tertiary rift basins of the Gulf of Thailand. The Leading Edge, 31, 630-634.

NIPI, (2016). Báo cáo: Kết thúc pha I-giai đoạn Tìm kiếm thăm dò lô 09-3/12, bể Cửu Long, thềm Lục địa Việt Nam.

Phan Thanh Liêm và Lê Hải An, (2013). "Nghiên cứu đối tượng turbidite Miocen giữa/muộn Pliocen khu vực lô 04-1 bể Nam Côn Sơn qua phân tích thuộc tính địa chấn đặc biệt", Tạp chí dầu khí, số 9, 8-15.

Satinder Chopra; Kurt J. Marfurt, (2007). Seismic attribute for prospect identification and reservoir characterization. Tulsa: Society of Exploration Geophysicists, 464

VSP, (2017). Báo cáo “Minh giải đặc biệt tài liệu địa chấn PSDM góc phương vị rộng 3D/4C trên lô 09-1" VSP. 